\title{
Factors associated with chronic lung disease in preterm infants
}

Mersey Regional Neonatal Intensive Care Unit,

Liverpool Maternity Hospital, Liverpool Hospital,

Correspondence to: Professor Cooke.

Accepted 16 April 1991

\begin{abstract}
Among 659 infants of 30 weeks' gestation or less born in a regional perinatal centre between 1983 and 1989, 195 were ventilated for four days or more and survived to $\mathbf{2 8}$ days, and 87 of these developed chronic lung disease. There was a sevenfold increase in the annual incidence of chronic lung disease over time. During the same period there were significant increases in the number of infants who survived, the incidence of septicaemia, and the use of parenteral lipid emulsions. Chronic lung disease was significantly associated with low birth weight, shorter gestation, duration of ventilation, vaginal delivery, sepsis, and the use of lipid. Respiratory and physiological measurements at 96 hours were significantly worse in infants who subsequently developed chronic lung disease. Initial logistic regression showed that gestation, arterial carbon dioxide tension $\left(\mathrm{PaCO}_{2}\right)$, and ventilation rate at 96 hours; and birth in 1988 or 1989 , were independently associated with chronic lung disease, but when septicaemia and use of lipid during the first 21 days were included, only gestational age (odds ratio $0.64,95 \%$ confidence interval (CI), 0.49 to $\mathbf{0 . 8 1}$ for each week) and use of lipid (odds ratio $8 \cdot 1,95 \% \mathrm{CI}, 2.32$ to $28 \cdot 0$ ) remained significantly associated with chronic lung disease.
\end{abstract}

The observed increase in incidence of chronic lung disease in this population was associated with earlier use of parenteral lipids in infants of very low gestation rather than with changes in population, survival, or ventilator treatment of respiratory distress syndrome.

Since the introduction of mechanical ventilation for the treatment of severe respiratory distress syndrome in preterm infants, the main complication limiting successful outcome has been chronic lung disease. This is usually defined as oxygen dependence at 28 days of life in an infant with a history of mechanical ventilation during the first week of life and characteristic radio-

Table 1 Inborn infants of 30 weeks' gestation or less who were ventilated for at least four days: condition at 28 days $(n=260)$. Figures are expressed as number $(\%)$

\begin{tabular}{lcccllll}
\hline & 1983 & 1984 & \multicolumn{1}{c}{1985} & 1986 & \multicolumn{1}{c}{1987} & \multicolumn{1}{c}{1988} & \multicolumn{1}{c}{1989} \\
\hline $\begin{array}{l}\text { Dead } \\
\text { Alive breathing oxygen } 4(31)\end{array}$ & $11(31)$ & $8(25)$ & $11(24)$ & $10(34)$ & $8(20)$ & $6(14)$ \\
Alive breathing air & $20(57)$ & $17(47)$ & $10(31)$ & $10(22)$ & $6(21)$ & $22(55)$ & $27(63)$ \\
\hline Total & 35 & 36 & 32 & 45 & 29 & 40 & 43
\end{tabular}

$\chi^{2}$ for trend $=25 \cdot 5, \mathrm{p}<0 \cdot 00001$. graphic changes in the lung fields. First described by Northway et al, ${ }^{1}$ it has variously been attributed to oxygen toxicity, barotrauma, infection, and the vulnerability of the lungs in very preterm infants. ${ }^{2}$

During recent years many centres have reported an increasing incidence of chronic lung disease, and the incidence varies considerably among centres. It has been suggested that the rising incidence is related to the survival of an increasingly vulnerable population of infants of lower gestational age who would previously have died. Differences in respiratory management have been suggested as one explanation for the variation in incidence among similar centres. ${ }^{3} \mathrm{~A}$ considerable rise in the numbers of infants with chronic lung disease has recently been observed in the Mersey regional neonatal intensive care unit, and this study was initiated to see if this change could be explained by changes in the population alone, or whether factors such as changes in management or increased survival played a part.

\section{Patients and methods}

Infants of 24 to 30 weeks' gestation admitted to the Mersey neonatal intensive care unit between 1 January 1983 and 31 December 1989 were included in the study if they were born in the hospital, were ventilated for at least the first four days of life, and survived to at least 28 days (table 1). Infants born at other hospitals and admitted later were not included because of incompleteness of early physiological data. Infants were considered to have chronic lung disease if they were oxygen dependent at 28 days, had received mechanical ventilation, and had characteristic radiographic changes.

Descriptive, respiratory, and physiological variables were abstracted from the clinical and intensive care records, which had been stored on microfiche. Descriptive variables included birth weight; gestation; sex; number of days ventilated; whether transferred to the centre in utero; use of pancuronium; use of parenteral lipid emulsions; singleton or multiple delivery; caesarean section; occurrence of pneumothorax, persistent ductus arteriosus, or septicaemia; and the presence of chronic lung disease. Persistent ductus arteriosus was defined as the presence of clinical signs sufficient to lead to a change in management such as fluid restriction, and septicaemia as a positive blood culture. Parenteral lipid emulsions (Intralipid 20\%, KabiVitrum) were given through peripheral or central lines at a rate of $5 \mathrm{ml} / \mathrm{kg} /$ day, increasing over four days to a maximum of $20 \mathrm{ml} / \mathrm{kg} / \mathrm{day}$. These variables were examined initially, together 
Table 2 Changes in proportions of study infants $(n=195)$ with septicaemia, receiving lipids, and requiring ventilation on day 10

\begin{tabular}{|c|c|c|c|c|c|c|c|c|c|}
\hline & 1983 & 1984 & 1985 & 1986 & 1987 & 1988 & 1989 & $\begin{array}{l}\chi^{2} \\
\text { for trend }\end{array}$ & p Value \\
\hline $\begin{array}{l}\text { Septicaemia } \\
\text { Lipid used for }<21 \text { day } \\
\text { Ventilated at day } 10\end{array}$ & $\begin{array}{r}11(46) \\
3(13) \\
6(25)\end{array}$ & $\begin{array}{l}14(56) \\
14(56) \\
10(40)\end{array}$ & $\begin{array}{l}17(71) \\
14(58) \\
16(67)\end{array}$ & $\begin{array}{l}24(71) \\
18(53) \\
12(35)\end{array}$ & $\begin{array}{r}14(74) \\
13(68) \\
7(37)\end{array}$ & $\begin{array}{l}26(81) \\
30(94) \\
22(69)\end{array}$ & $\begin{array}{l}27(73) \\
33(89) \\
23(62)\end{array}$ & $\begin{array}{r}7 \cdot 4 \\
45 \cdot 9 \\
8 \cdot 8\end{array}$ & $\begin{array}{c}0.006 \\
<0.0001 \\
0.003\end{array}$ \\
\hline Total & 24 & 25 & 24 & 34 & 19 & 32 & 37 & - & - \\
\hline
\end{tabular}

with respiratory and physiological variables measured at 6, 48, and 96 hours of age according to year of birth, for significant trends to change with time ( $\chi^{2}$ for trend) (table 2$)$. The same variables were then compared in infants with and without chronic lung disease (table 3), together with respiratory and physiological variables measured at 6,48 , and 96 hours of age (table 4). If a particular measurement had not been recorded exactly at one of the required times, the next recording was taken. All blood gas measurements were made in arterial samples and all blood pressure recordings were taken from catheters in the aorta or radial artery. Alveolar:arterial (A:a) ratios were computed from the blood gas measurements and the fractional inspiratory oxygen $\left(\mathrm{FIO}_{2}\right.$.)
The significance of differences was assessed with the $\chi^{2}$ test for categorical variables and the Mann-Whitney U test for continuous variables. The descriptive variables, the year of birth, and those respiratory and physiological variables that differed significantly between the two groups at the $5 \%$ level or less, were then entered in a logistic regression analysis (SPSS-X-Probit, Logit option ${ }^{5}$ ) and the regression coefficient and its standard error derived for each variable (table 5). The odds ratio and $95 \%$ confidence intervals $(\mathrm{CI})$ were calculated where appropriate. Because the greater number of days spent being ventilated in the group with chronic lung disease was thought to be partly a result of chronic lung disease rather than a cause, this variable was not included in the analysis.

Table 5 Results of logistic regression with chronic lung disease as dependent variable

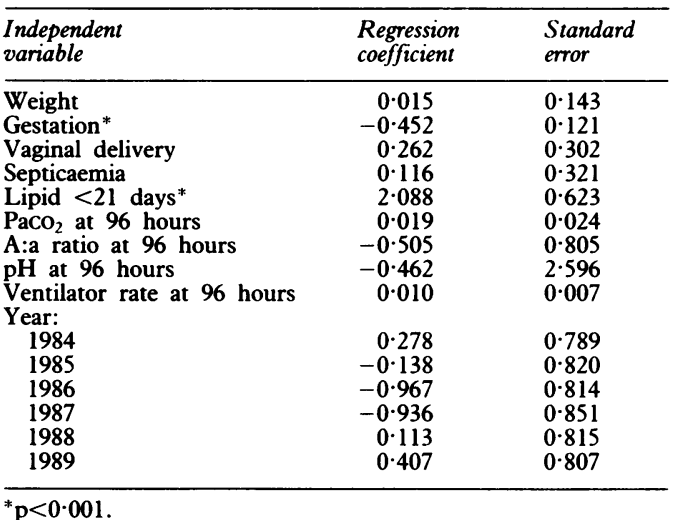

Table 3 Demographic variables and management in 195 infants with and without chronic lung disease. Figures are expressed as number (\%) except where otherwise stated

\begin{tabular}{lllc}
\hline & $\begin{array}{l}\text { Infants without } \\
\text { chronic lung disease } \\
(n=108)\end{array}$ & $\begin{array}{l}\text { Infants with } \\
\text { chronic lung disease } \\
(n=87)\end{array}$ & $p$ Value \\
\hline Median (range) weight (g) & $1208(612-1944)$ & $903(610-2000)$ & $<0.00001$ \\
Median (range) gestation (weeks) & $29(24-30)$ & $27(24-30)$ & $<0.00001$ \\
Multiple pregnancy & $22(20)$ & $18(21)$ & 0.99 \\
Caesarean section & $66(61)$ & $36(41)$ & 0.003 \\
Median (range) days ventilated & $7(4-50)$ & $25(4-300)$ & $<0.00001$ \\
Ventilated day 10 & $22(20)$ & $74(85)$ & 0.00001 \\
Male & $62(57)$ & $53(61)$ & 0.52 \\
In utero transfer & $72(67)$ & $53(61)$ & 0.87 \\
Pancuronium & $72(67)$ & $67(77)$ & $<0.00001$ \\
Lipid <21 days & $43(40)$ & $82(94)$ & 0.25 \\
Pneumothorax & $28(26)$ & $40(34)$ & 0.37 \\
Persistent ductus arteriosus & $43(40)$ & $72(83)$ & 0.00009 \\
Septicaemia & $61(56)$ & & \\
\hline
\end{tabular}

Table 4 Respiratory measurements at 6, 48, and 96 hours in 195 infants with and without chronic lung disease. Values are expressed as median (range)

\begin{tabular}{|c|c|c|c|c|c|}
\hline \multirow[b]{2}{*}{$\mathrm{FIO}_{2}$} & \multirow{2}{*}{$\begin{array}{l}\begin{array}{l}\text { Time } \\
\text { (hours) }\end{array} \\
6 \\
48 \\
96\end{array}$} & \multicolumn{2}{|c|}{$\begin{array}{l}\text { Infants without } \\
\text { chronic lung disease } \\
(n=108)\end{array}$} & \multicolumn{2}{|c|}{$\begin{array}{l}\text { Infants with } \\
\text { chronic lung disease } \\
(n=87)\end{array}$} \\
\hline & & $\begin{array}{l}0.75 \\
0 \cdot 70 \\
0.40\end{array}$ & $\begin{array}{l}(0 \cdot 21-1 \cdot 00) \\
(0 \cdot 28-1 \cdot 00) \\
(0 \cdot 21-1 \cdot 00)\end{array}$ & $\begin{array}{l}0.85 \\
0.75 \\
0.55\end{array}$ & $\begin{array}{l}(0 \cdot 21-1 \cdot 00) \\
(0 \cdot 21-1 \cdot 00) \\
(0 \cdot 21-1 \cdot 00)\end{array}$ \\
\hline Ventilator rate/min & $\begin{array}{l}6 \\
48 \\
96^{*}\end{array}$ & $\begin{array}{l}40 \\
57 \\
30\end{array}$ & $\begin{array}{l}(0-100) \\
(0-100) \\
(0-90)\end{array}$ & $\begin{array}{l}40 \\
55 \\
40\end{array}$ & $\begin{array}{l}(6-100) \\
(0-120) \\
(0-131)\end{array}$ \\
\hline Peak airway pressure $\left(\mathrm{cm} \mathrm{H}_{2} \mathrm{O}\right)$ & $\begin{array}{r}6 \\
48 \\
96\end{array}$ & $\begin{array}{l}20 \\
20 \\
18\end{array}$ & $\begin{array}{l}(0-45) \\
(0-34) \\
(0-25)\end{array}$ & $\begin{array}{l}22 \\
22 \\
18\end{array}$ & $\begin{array}{l}(15-44) \\
(4-41) \\
(0-32)\end{array}$ \\
\hline $\mathrm{PaO}_{2}(\mathbf{k P a})$ & $\begin{array}{r}6 \\
48 \\
96\end{array}$ & $\begin{array}{l}7 \cdot 86 \\
8 \cdot 40 \\
9 \cdot 86\end{array}$ & $\begin{array}{l}(3 \cdot 07-23 \cdot 50) \\
(3 \cdot 20-28 \cdot 80) \\
(4 \cdot 00-23 \cdot 05)\end{array}$ & $\begin{array}{l}9 \cdot 06 \\
8 \cdot 53 \\
8.66\end{array}$ & $\begin{array}{l}(3 \cdot 07-34 \cdot 70) \\
(4 \cdot 80-21 \cdot 20) \\
(4 \cdot 27-19 \cdot 20)\end{array}$ \\
\hline $\mathrm{PaCO}_{2}(\mathrm{kPa})$ & $\begin{array}{l}90 \\
68 \\
48 \\
96\end{array}$ & $\begin{array}{l}5 \cdot 86 \\
5 \cdot 07 \\
5 \cdot 73 \\
5 \cdot 07\end{array}$ & $\begin{array}{l}(4 \cdot 00-23 \cdot 05) \\
(2 \cdot 93-13 \cdot 20) \\
(3 \cdot 07-10 \cdot 00) \\
(2 \cdot 13-9 \cdot 73)\end{array}$ & $\begin{array}{l}8 \cdot 66 \\
5 \cdot 07 \\
5 \cdot 60 \\
5 \cdot 60\end{array}$ & $\begin{array}{l}(4 \cdot 27-19 \cdot 20) \\
(2 \cdot 67-8 \cdot 13) \\
(2 \cdot 67-10 \cdot 90) \\
(2 \cdot 53-9 \cdot 06)\end{array}$ \\
\hline pH & $\begin{array}{l}6 \\
48 \\
96+\end{array}$ & $\begin{array}{l}7 \cdot 36 \\
7 \cdot 27 \\
7 \cdot 32\end{array}$ & $\begin{array}{l}(6 \cdot 92-7 \cdot 52) \\
(6 \cdot 99-7 \cdot 46) \\
(6 \cdot 99-7 \cdot 60)\end{array}$ & $\begin{array}{l}7 \cdot 34 \\
7 \cdot 27 \\
7 \cdot 30\end{array}$ & $\begin{array}{l}(7 \cdot 00-7 \cdot 50) \\
(7 \cdot 01-7 \cdot 48) \\
(7 \cdot 15-7 \cdot 42)\end{array}$ \\
\hline A:a ratio & $\begin{array}{c}6 \\
48 \\
96+\end{array}$ & $\begin{array}{l}0 \cdot 143 \\
0 \cdot 140 \\
0.283\end{array}$ & $\begin{array}{l}(0.038-0.646) \\
(0.038-0.506)\end{array}$ & $\begin{array}{l}0 \cdot 147 \\
0.136\end{array}$ & $\begin{array}{l}(0.035-0.621) \\
(0.059-0.680)\end{array}$ \\
\hline Mean arterial blood pressure $(\mathrm{mmHg})$ & $\begin{array}{c}96 \ddagger \\
6 \\
48 \\
96\end{array}$ & $\begin{array}{l}0 \cdot 283 \\
36 \\
40 \\
45\end{array}$ & $\begin{array}{l}(0 \cdot 065-0 \cdot 990) \\
(21-58) \\
(25-60) \\
(29-76)\end{array}$ & $\begin{array}{l}0 \cdot 210 \\
34 \\
39 \\
42\end{array}$ & $\begin{array}{l}(0 \cdot 060-0 \cdot 950) \\
(16-56) \\
(23-59) \\
(22-73)\end{array}$ \\
\hline
\end{tabular}

${ }^{*} p=0.03,{ }^{* *} p=0.002, \nmid p=0.012$, and $\neq p=0.009$. 
Results

During the seven year period studied 659 infants of between 24 and 30 weeks' gestation were born in the hospital and admitted to the neonatal intensive care unit. Of these, 195 infants were ventilated for four or more days and survived to at least 28 days of life, and these form the study group. Eighty seven developed chronic lung disease as defined. There were no significant differences with time in the distribution of gestational age, birth weight, sex, incidence of caesarean section, multiple gestation, in utero transfer, or male sex, in the frequency of use of pancuronium, occurrence of pneumothorax or persistent ductus arteriosus, or in any of the physiological or respiratory variables. There was a sevenfold increase in the incidence of chronic lung disease (table 1), together with an increase in the incidence of septicaemia, in the use of lipid emulsions, and in the proportion of infants still being ventilated on day 10 (table 2 ).

The characteristics of the infants in the study group are shown in table 3, grouped according to whether they developed chronic lung disease or not. Those that did were lighter and less mature, were less likely to have been delivered by caesarean section, were ventilated longer, and were more likely to have received parenteral lipid during the first 21 days of life and to have had septicaemia. The respiratory and physiological variables are shown in table 4. Significant differences between infants with and without chronic lung disease were seen only at 96 hours when the ventilator rate, peak airway pressure, and arterial carbon dioxide tension $\left(\mathrm{PaCO}_{2}\right)$ were higher, and the $\mathrm{pH}$ and $\mathrm{A}:$ a ratio were lower. When the descriptive variables, the year of birth, and those respiratory and physiological variables that differed significantly between the two groups were entered in a logistic regression with chronic lung disease as the dependent variable, only gestation, birth in 1988 or 1989 , and $\mathrm{PaCO}_{2}$ and ventilator rate at 96 hours were independently associated with chronic lung disease. The inclusion of septicaemia as an independent variable left only gestational age and birth in 1988 and 1989 independently associated with chronic lung disease, and the inclusion of lipid use in the first 21 days left only gestational age (odds ratio $0.64,95 \%$ CI 0.49 to 0.81 , for each week) and use of lipid at $<21$ days (odds ratio $8 \cdot 1,95 \% \mathrm{CI}$ $2 \cdot 32$ to $28 \cdot 0$ ) with significant associations (table 5).

\section{Discussion}

Neonatal intensive care has been described as a

Table 6 Numbers of neonatal survivors who received parenteral lipid, and time of start by year of birth

\begin{tabular}{lccccccc}
\hline & 1983 & 1984 & 1985 & 1986 & \multicolumn{1}{l}{1987} & 1988 & 1989 \\
\hline $0-9$ days & 1 & 0 & 1 & 1 & 5 & 19 & 26 \\
10-21 days & 2 & 14 & 13 & 17 & 8 & 11 & 7 \\
Over 21 days or never & 20 & 11 & 10 & 16 & 6 & 2 & 4 \\
\hline Total & 24 & 25 & 24 & 34 & 19 & 32 & 37
\end{tabular}

$\chi^{2}$ for trend $72 \cdot 6, p<0.00001$ continuing experiment, and certainly many of the factors that may affect outcome either for good or ill are constantly changing. When an adverse outcome such as chronic lung disease in preterm survivors of intensive care is seen to increase, it is often difficult to find out whether the change is the result of changes in the population served, in survival, or in factors relating to techniques of management. Chronic lung disease in inborn infants of 30 weeks' gestation or less and ventilated for four days or longer has apparently risen sevenfold during a seven year period, and mainly in the last two years. When demographic variables significantly associated with chronic lung disease in this group were taken into account in the logistic regression the years 1988 and 1989 remained significantly associated with chronic lung disease, suggesting that factors other than demographic changes were responsible for the observed change in incidence of chronic lung disease.

Though there was a clear trend to increased neonatal survival in this high risk group (table 1), this cannot account fully for the observed increase in chronic lung disease. If this were so, the numbers of neonatal deaths together with the number of infants in oxygen at 28 days should form a similar proportion of the total population in each year. As seen in table 1 , this proportion increased during the seven year period from $42 \%$ to $77 \%$. A number of respiratory and physiological measurements made at 96 hours of age were significantly associated with chronic lung disease. In the logistic regression only $\mathrm{PaCO}_{2}$ and respiratory rate at 96 hours remained significantly associated with chronic lung disease before septicaemia and lipid use were taken into account. The improved survival of the very immature that has clearly occurred, especially in the last two years of this study, could have been the result of a more intensive attitude to ventilation of this group of infants. Kraybill et al suggested that the observed variation in the incidence of chronic lung disease among a number of neonatal intensive care units in the United States was attributable to differences in the intensity of mechanical ventilation, as shown by the lower $\mathrm{PaCO}_{2}$ at 48 hours of age reported from centres with higher rates of chronic lung disease. ${ }^{4}$ The differences seen in this study were in the opposite direction, implying that infants who developed chronic lung disease were sicker at 96 hours of age rather than overventilated at 48 hours. The lack of an independent association between respiratory variables and the occurrence of chronic lung disease as previously shown suggests that while methods of ventilation may account for differences in chronic lung disease rates among centres, they do not explain the recent increases in incidence within centres.

The increase in the incidence of septicaemia was almost entirely related to an increase in coagulase negative staphylococcal infection. Septicaemia, though strongly associated with chronic lung disease in the univariate analysis, failed to achieve independent association in the logistic regression model after lipid use had been allowed for. Though septicaemia could be 
causally associated with chronic lung disease, it is also probable that infants who developed chronic lung disease were more prone to infection. The use of lipid emulsions during the first 21 days of life was strongly associated with chronic lung disease, and when it was entered in the regression model it was the only factor to account for the higher incidence of chronic lung disease in 1988 and 1989.

The association between chronic lung disease and the use of lipid could be explained by lipid being given mainly to sicker infants. Examination of lipid prescription in this group during the study period, however, showed a pronounced change in the age at which it was started. In particular, much earlier use of lipid was made in the last two years (table 6) in the absence of any significant change in the early severity of illness as measured by the respiratory and physiological variables. The use of lipid emulsions in sick preterm infants has been associated with higher rates of coagulase negative staphylococcal sepsis, ${ }^{6}$ as was the case in this study, when $81 \%$ of infants receiving lipid became septicaemic, compared with $40 \%$ of those who did not $(\mathrm{p}<0.0001)$. Giving lipid to preterm infants is associated with an excess generation of free radical induced lipid peroxidation, and thromboxane production, ${ }^{7}$ and free radical induced lung damage has been proposed as a factor in the genesis of chronic lung disease. ${ }^{8}$ Recently a small clinical trial of lipid given for five days to preterm infants undergoing intensive care showed a significant excess of chronic lung disease and retinopathy in treated infants compared with controls. ${ }^{9}$

The earlier use of parenteral lipid solutions on this unit was introduced because of concern over poor growth in these sick, very low birthweight infants when amino acids and dextrose/electrolyte solutions alone were used for nutrition. It is likely that this exposed a large number of infants in the earlier stages of hyaline membrane disease to lipid, when they were most vulnerable to lung injury, and that this change in practice accounted for the increase in chronic lung disease seen in recent years.

Until further evidence is available, the use of parenteral lipid emulsions should be restricted to older preterm infants, or to those without respiratory symptoms. In sick preterm infants any theoretical gains made from early parenteral lipid infusion are outweighed by an increase in the incidence of chronic lung disease in the following weeks and months.

1 Northway WH, Rosan RC, Porter DY. Pulmonary disease following respirator therapy of hyaline membrane disease; following respirator therapy of hyaline membrane disease; bronch.

2 Boynton BR. Epidemiology of bronchopulmonary dysplasia. In: Merritt TA, Northway WH, Boynton BR, eds. Bronchopulmonary dysplasia. Contemporary issues in fetal and neonatal medicine. No 4. Boston: Blackwell Scientific Publications, 1988: 19-32.

3 Avery ME, Tooley WH, Keller JB. Is chronic lung disease in low birthweight infants preventable? A survey of eight centres. Pediatrics 1987;79:26-30

4 Kraybill EN, Runyan DK, Bose CL, Khan JH. Risk factors for chronic lung disease in infants with birthweights of 751 to 1000 grams. F Pediatr 1989;115:115-20.

5 SPSS-X users guide. 3rd Ed. Chicago: SPSS Inc, 1988.

6 Freeman J, Goldmann DA, Smith NE, Sidebottom DG, Epstein MF, Platt R. Association of intravenous lipid emulsion and coagulase-negative staphylococcal bacteraemia in neonatal intensive care units. $N$ Engl f Med 1990;323: in neon. $1-8$.

7 Pereira GR, Fox WW, Stanley CA, Barker L, Schwartz JG. Decreased oxygenation and hyperlipemia during intravenous fat infusions in premature infants. Pediatrics 1980;66:26-30

8 Saugstad OD. Hypoxanthine as an indicator of hypoxia; its role in health and disease through free-radical production. Pediatr Res 1988;23:143-50.

9 Hammerman C, Aramburo MJ. Decreased lipid intake reduces morbidity in sick premature neonates. $\mathcal{f}$ Pediatr 1988;113:1083-8. 